\title{
Genetic polymorphism of GSTM1 in women with breast cancer and interact with reproductive history and several clinical pathologies
}

\author{
JOSÉ JUVENAL LINHARES ${ }^{1}$, ISMAEL DALE COTRIM GUERREIRO DA SILVA ${ }^{2}$, \\ NAIARA C. NOGUEIRA DE SOUZA ${ }^{2}$, EMMANUELLE COELHO NORONHA ${ }^{1}$, ODAIR \\ FERRARO $^{1}$, CRISTINA VALLETA DE CARVALHO, EDMUND CHADA BARACAT ${ }^{2}$ \\ and FAUSTO FARAH BARACAT ${ }^{1}$
}

\author{
${ }^{1}$ Division of Obstetrics and Gynecology, Hospital do Servidor Público Estadual São Paulo, Brazil "Francisco \\ Morato Oliveira" (HSPE-FMO) \\ ${ }^{2}$ Molecular Gynecology Laboratory, Department of Gynecology, Federal University of São Paulo, Brazil
}

\begin{abstract}
Due to the conflicting results regarding the association between breast cancer and the GSTM1 null mutation, our aim was to research this association in a Brazilian population and correlations with smoking, reproductive history and several clinical pathologies. A case-control study was performed on 105 women with breast cancer and 278 controls. Extraction of DNA was accomplished according to the protocol of the GFX ${ }^{\circ}$ kit and polymorphism analysis by the PCR technique. The control and experimental groups were compared and statistical analysis assessed by $\mathrm{X}^{2}$ or Fisher's exact test. The deletion in the GSTM1 gene in the breast cancer group had a prevalence of $32(30.4 \%)$ individuals with the presence of null mutation. In the control group, the null mutation was present in $104(37.4 \%)$ women. Upon comparison of the two groups, no statistically significant difference of the GSTM1 gene was observed, with an odds ratio (OR) of $0.74,95 \%$, confidence interval $(\mathrm{CI}) 0.45-1.20, \mathrm{p}=0.277$. The results conclusively show that single gene GSTM1 polymorphisms do not confer a substantial risk of breast cancer to its carriers. Furthermore, in this study no correlation was found between GSTs and smoking, reproductive history and several clinical pathologies with respect to cancer risk.
\end{abstract}

Key terms: Breast cancer, genetic polymorphisms, GSTM1.

\section{INTRODUCTION}

Studies have shown that prevention is important for reducing incidence and mortality rates in breast cancer. Treatment therapies are only slightly effective in reducing mortality; prevention is clearly the best strategy to decrease the incidence of breast cancer (Ruiz et al., 2001).

The inclusion of the genetic analysis of the polymorphisms in the epidemiology of breast cancer is of particular interest because it allows the identification of subpopulations of people with increased susceptibility to cancer induced by carcinogens. It is also able to establish the tolerable limits of exposure to certain agents and allows the establishment of differentiated guidelines to be followed and diagnosis in function of the genotypes of risk (Ruiz et al., 2001).

Glutathione S-transferases (GSTs) are a supergene family of enzymes involved in phase II of biotransformation, which is characterized by the conjugation of endogenous water-soluble compounds to lipophilic substrates. GSTs catalyze the conjugation of glutathione, a tripeptide consisting of glycine, glutamic acid and cysteine, to electrophilic compounds, resulting in less reactive and more readily excreted glutathione conjugates. Substrates 
of GST-catalyzed reactions include precarcinogens, such as polycyclic aromatic hydrocarbons, pharmacological drugs such as paracetamol, chemotherapeutic agents and free radicals generated during oxidative stress. GSTs have recently been shown to act as inhibitors of the jun-kinase pathway, which is an important signaling mechanism for the activation of cytoprotective genes (Rossini et al., 2002). With regard to hormone metabolism, it is also important to mention that GSTs are involved in estrogen peroxidation and a shortage seems to enhance estrogen tissue exposure (Cavalieri et al., 1997).

Human cytosolic GSTs have been well characterized; they are polymorphic and have ethnic-dependent polymorphism frequencies. The GSTM1 gene is located on chromosome $1 \mathrm{p} 13.3$, and 20 to $50 \%$ of individuals do not express the enzyme due to a homozygous gene deletion known as the GSTM1*0, or null allele (Seidgard et al., 1999). The percentage of individuals who do not express the enzyme is higher in Caucasian and Asian populations than it is among people of African descent (Maugard et al., 1998). GSTM1 is involved in the detoxification of polycyclic aromatic hydrocarbons and other mutagens, and cells from GSTM1 null individuals are more susceptible to DNA damage caused by these agents (Rossini et al., 2002).

Rossini et al. (2002) found that $42.1 \%$ of a general Brazilian population (healthy men and women) were homozygotic for the GSTM1 deletion. In a study with Brazilian women, Da Fonte de Amorim et al. (2002) showed that this polymorphism may decrease the risk of breast cancer among these individuals $(\mathrm{OR}=0.30,95 \% \mathrm{CI}=0.12-0.76)$.

GSTM1 polymorphism has been associated with different susceptibilities of some forms of cancer, particularly those caused by smoking. Among the environmental factors, exposure to polycyclic aromatic hydrocarbons (PHAs) has been suggested to contribute to breast cancer formation (Da Fonte de Amorim et al., 2002). The enzymes of the GST superfamily, especially GSTM1, can metabolize PHAs and thereby block their binding to DNA (Cavaliere et al., 1997,
Perera et at., 1995 and Da Fonte de Amorim et al., 2002).

Because of the conflicting results regarding the association between breast cancer and the GSTM1 null mutation, as well as the existence of just one Brazilian study, we aimed to research this association and interaction with smoking, reproductive history and several clinical pathologies in a Brazilian population.

\section{MATERIALS AND METHODS}

\section{Patients and samples}

We conducted a case-control study with the comparison of the frequencies of genotypes of GSTM1 polymorphism of 383 eligible Brazilian women: 105 women with surgically and histologically confirmed breast cancer and 278 healthy control women. The 105 cases with breast cancer were admitted and treated at the Mastology Section, Division of Gynecology and Obstetrics, in the Hospital do Servidor Publico Estadual São Paulo-Brazil Francisco Morato Oliveira (HSPE - FMO) from April to October 2004. The study protocol for the use of human subjects in research was approved by committees of relevant institutions.

The control group for Brazilian genotype frequency consisted of 278 women with no prior history of breast cancer, admitted and treated at the Gynecologic Section, Division of Gynecology and Obstetrics, in the Hospital do Servidor Publico Estadual São Paulo-Brazil Francisco Morato Oliveira (HSPE - FMO) and Menopause Section Department of Gynecology, Federal University of São Paulo, Brazil from April to October 2004, after clinical and mammographic examination. All samples were obtained after informed consent of the participants prior to their inclusion in the study.

A structured questionnaire was used to elicit detailed information on demographic factors, race (Caucasian and those of blackAfrican descent) menstrual and reproductive histories, tobacco use and family history of breast cancer. The patients 
with breast cancer were also measured for their clinical stage, axillary lymph node status and Smith-Bloom and Richardson (SBR) histological grade.

\section{Genotyping}

Buccal cells used as the source of DNA were extracted by using the GFX kit (GE Healthcare) according to manufacturer's instructions. For the detection of GSTM1 polymorphism, we used the polymerase chain reaction (PCR) methodology with the following oligonucleotide primers in the same reaction tube: 5' - GAA CTC CCT
GAA AAG CTA AAG C - 3'(forward), 5' GTT GGG CTC AAA TAT ACG GTG G 3’(reverse), 5' - CAA CTT CAT CCA GGT TCA CC - 3'(forward) and 5' - GAA GAG CCA AGG ACA GGT AC - 3' for GSTM1 and beta-globin genes respectively. PCR conditions were an initial denaturing step at $94^{\circ} \mathrm{C}$ for 3 minutes, followed by 40 cycles at $94^{\circ} \mathrm{C}$ for 1 minute, $55^{\circ} \mathrm{C}$ for 1 minute, and $72^{\circ} \mathrm{C}$ for 1 minute and final extension at $72^{\circ} \mathrm{C}$ for 7 minutes. A negative control without template DNA was used in each run. The PCR products were resolved on $2 \%$ agarose gel stained with ethidium bromide (Fig. 1).

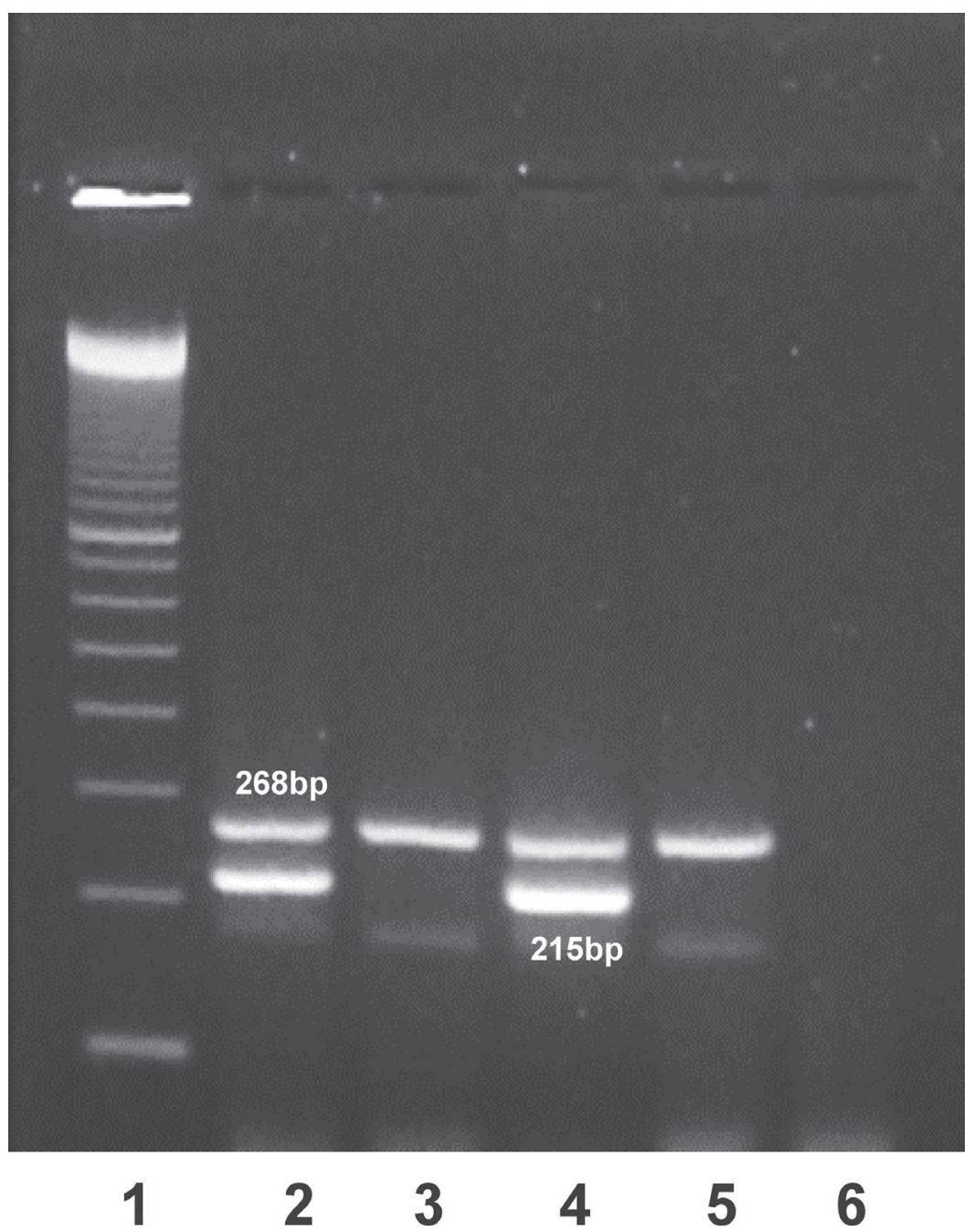

Figure 1: 2\% agarose/ethidium bromide gel. 1 -100Bp marker; 2 and 4 - GSTM1 gene (beta globin - 268Bp e GSTM1 - 215Bp); 3 and 5 -GSTM1 null deletion (beta globin - 268Bp); 6 negative control. 


\section{Statistical analysis}

Data was analyzed using computer software SPSS for Windows (version 7.5) and Epi Info (version 6.04a). Statistical differences between mean values of the two groups were evaluated by using the $\mathrm{X}^{2}$ test or Fisher's exact test. A 5\% level of significance was used in the analysis. The odds-ratio was estimated by the logistic regression model, assuming $95 \%$ as the confidence interval (CI), using the Woolf approximation.

We stratified the analysis according to age, race, age at onset of menstruation, menopausal status, family history, smoking habit and clinical status, axillary lymph nodes status and histological grade SBR. Odds ratios (OR) were calculated as a measure of the association between GSTM1 polymorphism and risk of breast cancer.

\section{RESULTS}

The proportion of individuals from the breast cancer group with GSTM1 null deletion was $30.4 \%$ (32 patients). In the control group, we observed that 104 patients $(37.4 \%)$ presented the null deletion. The difference between these two groups was not statistically significant. The GSTM1 null deletion did not increase the risk of breast cancer development (odds ratio (OR) $0.74,95 \%$ confidence interval (CI) $0.45-1.20, p=0.277$ ) (Fig. 2).

Furthermore, we did not find a statistically significant difference between the studied groups in relation to age, race, onset of menstruation, menopausal status, age at first birth, number of pregnancies, parity, family history or smoking habits (Table I).

Table II shows the distribution of the genotype frequencies of cases and controls by age, menopausal status, race and parity. There was no overall risk associated with breast cancer.

We did not find a statistically significant difference in the breast cancer group with respect to age, race, onset of menstruation, menopausal status, family history or smoking habits as shown in Table III.

In the breast cancer group studied, we did not find significant differences in relation to clinical stage, axillary lymph nodes status and histologically grade (Table IV).

\section{DISCUSSION}

One of the primary reasons to study GSTM1 polymorphisms and their possible correlation to breast cancer is the fact that in industrial and highly populated areas such as São Paulo (17 million people), the lack of an effective detoxification system might be a risk factor for breast cancer. Indeed, the GST family catalyzes reactive carcinogenic intermediates that are produced through the metabolism of environmental toxins by detoxification enzymes. The genes of the GST families are under the control of the aryl hydrocarbon receptor, which binds toxic chemicals such as dioxin, an environmental pollutant believed to be involved in breast cancer development (Perera et al., 1995).

In addition, GST is also involved in estrogen metabolism and its absence might expose estrogen-sensitive tissues to a higher degree of stimulation (Cavaliere et al., 1997). The influence of this polymorphism was already determined in other cancers such as lung cancer and ovarian cancer (Perera et al., 1995), which lead to the authors hypothesize that a GSTM1 null deletion contributes to the genesis of breast cancer.

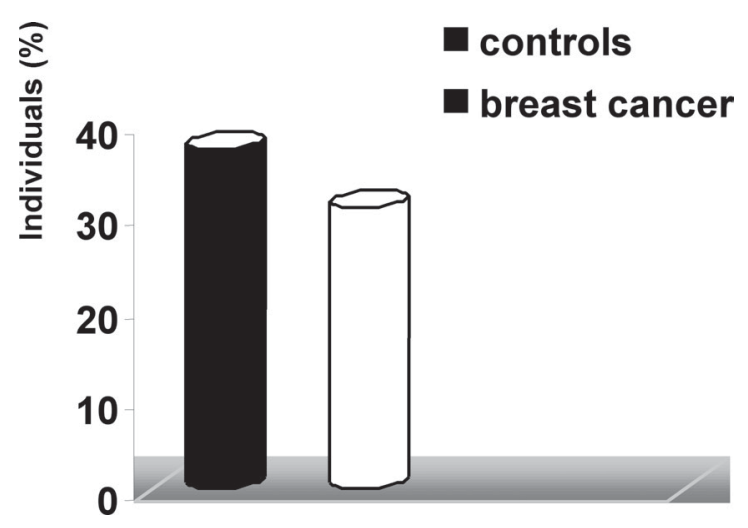

Figure 2: Presence of GSTM1 null deletion in the control group of Brazilian women without breast cancer $(37.4 \%)$ and patients with breast cancer $(30.4 \%$ ) (odds ratio (OR) $0.74,95 \%$ confidence interval (CI) $0.45-1.20, p=0.277)$. 


\section{TABLE I}

Comparison of cases $(n=105)$ and controls $(n=278)$ according to demographic factors and major risk factors for breast cancer.

\begin{tabular}{lccc}
\hline & Cases $(\mathrm{N}=105)$ & Controls $(\mathrm{N}=278)$ & Values p and O.R \\
\hline Age (mean) & $57.7+13.5$ & $55.5+10.3$ & $\mathrm{p}=0.453$ \\
Race (n) & & & \\
Caucasian & $85.0(105)$ & $196.0(278)$ & $\mathrm{p}=0.435$ \\
Black & $20.0(105)$ & $82.0(278)$ & $\mathrm{p}=0.126$ \\
Age at first menstruation (mean) & $13.0+1.7$ & $13.2+2.3$ & $p=0.861$ \\
Menopause (n) & & & \\
Pre & 34 & 85 & $\mathrm{p}=0.804$ \\
Pre Post & 71 & 193 & \\
Age at First full term pregnancy at age (mean) & 23.2 & 24.5 & $\mathrm{p}=0.905$ \\
Pregnancy (mean) & & & \\
Parity (n) & $2.7+2.3$ & $2.8+2.4$ & \\
Nulliparous & & & \\
Multiparous & 14.0 & 34.0 & \\
First-degree family history breast cancer (n) & 91.0 & 244.0 & \\
Yes & & & \\
No & 11.0 & 2500 & \\
Cigarette smoking (n) & 94.0 & 253.0 & \\
Yes & & & \\
No & 22 & 194 & \\
\hline
\end{tabular}

${ }^{1} \mathrm{p}<0,05$ were considered significant.

2 Includes first degree relatives (mother, sisters or daughters)

TABLE II

Comparasion of genotype frequencies among Brazilian breast cancer patients and controls.

\begin{tabular}{|c|c|c|c|c|c|c|c|}
\hline \multirow[t]{2}{*}{ Characteristics } & \multicolumn{3}{|c|}{ Cases $(\mathrm{N}=105)$} & \multicolumn{3}{|c|}{ Controls $(\mathrm{N}=278)$} & \multirow[b]{2}{*}{$95 \% \mathrm{CI}$} \\
\hline & $\mathrm{N}$ & GSTM1 null & $\mathrm{N}$ & GSTM1 null & Values $p$ & O.R & \\
\hline Age $<50$ anos & 31 & 13 & 079 & 36 & 0.832 & 0.862 & $0.37-1.99$ \\
\hline Menopause & 71 & 19 & 193 & 68 & 0.237 & 0.671 & $0.36-1.22$ \\
\hline Caucasian race & 85 & 24 & 196 & 74 & 0.135 & 0.648 & $0.37-1.12$ \\
\hline Nulliparous & 14 & 06 & 034 & 09 & 0.315 & 2.080 & $0.56-7.67$ \\
\hline
\end{tabular}

${ }^{1} \mathrm{p}<0,05$ were considered significant

$2 \mathrm{X}^{2}$ Test: Odds-ratio was estimated by the logistic regression model, assuming $95 \%$ as the confidence interval (CI), using the approximation of Woolf. 


\section{TABLE III}

Descriptive characteristics of the breast cancer cases according to GSTM1 genotypes and statistical analysis of the variables.

\begin{tabular}{|c|c|c|c|}
\hline Variables & Null Deletion & Normal & Statistics $p$ and OR $(95 \% \mathrm{CI})$ \\
\hline \multicolumn{4}{|l|}{ Age at diagnosis } \\
\hline$<50$ years & $13(28)$ & $15(28)$ & $p=0.03$ \\
\hline$>50$ years & $19(77)$ & $58(77)$ & O.R.= $2.64(\mathrm{CI}: 1.06-6.54)$ \\
\hline \multicolumn{4}{|l|}{ Race } \\
\hline Caucasian & $24(85)$ & $61(85)$ & $p=0.41$ \\
\hline Black & $08(20)$ & $12(20)$ & $O . R .=0.59(C I: 0.21-1.62)$ \\
\hline \multicolumn{4}{|c|}{ Age at first menstruation } \\
\hline$<12$ years & $13(34)$ & $21(34)$ & $P=0.26$ \\
\hline$>12$ years & $19(71)$ & $52(71)$ & $O . R=1.69(C I: 0.71-4.03)$ \\
\hline \multicolumn{4}{|l|}{ Menopausal status } \\
\hline Pre menopause & $13(34)$ & $21(34)$ & $P=0.26$ \\
\hline After menopause & $19(71)$ & $52(71)$ & $O . R=1.69(C I: 0.71-4.03)$ \\
\hline \multicolumn{4}{|c|}{ First-degree family history breast cancer } \\
\hline Yes & $04(15)$ & $11(15)$ & $p=1.00$ \\
\hline No & $28(90)$ & $62(90)$ & $O . R=0.80(C I: 0.23-2.75)$ \\
\hline \multicolumn{4}{|l|}{ Cigarette smoking } \\
\hline Yes & $08(22)$ & $14(22)$ & $p=0.63$ \\
\hline No & $24(83)$ & $59(83)$ & $O . R=1.40(C I: 0.52-3.78)$ \\
\hline
\end{tabular}

${ }^{1} \mathrm{p}<0,05$ were considered significant;

${ }^{2} \mathrm{X}^{2}$ Test: Odds-ratio was estimated by the logistic regression model, assuming $95 \%$ as the confidence interval (CI), using the approximation of Woolf.

TABLE IV

Clinical and histological characteristics of breast cancer cases according to GSTM1 genotypes and statistical analysis of the variables.

\begin{tabular}{|c|c|c|c|}
\hline Variables & Null Deletion & Normal & Statistics $\mathrm{p}$ and OR $(95 \% \mathrm{CI})$ \\
\hline \multicolumn{4}{|c|}{ Clinic stage $(\mathrm{N})$} \\
\hline I / II & $15(58)$ & $43(58)$ & $p=0.29$ \\
\hline III / IV & $17(47)$ & $30(47)$ & $O . R=0.61(C I: 0.26-1.42)$ \\
\hline \multicolumn{4}{|c|}{ Axillary lymph nodes status (N) } \\
\hline Positive & $22(64)$ & $42(64)$ & $p=0.38$ \\
\hline Negative & $10(41)$ & $31(41)$ & $O . R=1.62(C I: 0.67-3.91)$ \\
\hline \multicolumn{4}{|c|}{ Histological grade SBR (N) } \\
\hline grade 1 & $09(29)$ & $20(29)$ & $p=1.00$ \\
\hline grade 2,3 & $23(76)$ & $53(76)$ & $O . R=1.03(C I: 0.41-2.62)$ \\
\hline
\end{tabular}

${ }^{1} \mathrm{p}<0,05$ were considered significant;

${ }^{2} \mathrm{X}^{2}$ Test: Odds-ratio was estimated by the logistic regression model, assuming $95 \%$ as the confidence interval (CI), using the approximation of Woolf. 
In a study of Brazilian women, da Fonte de Amorim et al. (2002) indicated that this polymorphism may decrease the risk of breast cancer among these individuals (128 patients and 256 controls), with $\mathrm{OR}=0.30$. However, this study did not make any correlation between the polymorphism and clinical aspects such as reproductive variables and clinical stage, as well as histopathological findings such as lymph node status and histological grade. Furthermore, the statistical analysis suggested that this polymorphism may decrease the development of breast cancer, whereas the null GSTM1 genotypes presented a trend for breast cancer risk.

The study presented here showed a similar number of cases and a greater number of controls within the Brazilian population (105 women with breast cancer and 278 controls) and is the first Brazilian study to investigate a correlation between GSTM1 polymorphism and reproductive history, along with several aspects of clinical pathology.

Our findings do not support a direct interaction between GSTM1 null deletion and breast cancer incidence $30.4 \%$ in the breast cancer group versus $37.4 \%$ ion the control group). There is no significant association between case and control groups $(p=0.277$ and $O R=0.74)$ and these results are in agreement with several articles from recent literature (Egan et al., 2004; Sull et al., 2004; Vogl et al., 2004).
On the other hand, data obtained by Da Fonte de Amorim et al. (2002), Milikan et al. (2000), Gudmundsdottir et al. (2001) and Curran et al. (2000) showed a decreased risk for breast cancer development among their study population (Table V). Increased risk, however, was described by Parl (2005) with and odds ratio of $2.83(95 \%$ confidence interval 1.45-5.59). The same increase in breast cancer risk was observed by other authors such as Park et al. (2003, 2004).

One of the reasons for a non-correlation with breast cancer might be the extreme racial mixing in the Brazilian population. Because of ethnic variations, it is possible that different variants may be genetically linked with different mutations. Therefore, care must be taken when analyzing data from different population studies.

The differences in the associations of the GSTM1 genotype with breast cancer suggest that the role played by GSTM1 in carcinogenesis may vary for different places all over the world. Indeed, environmental variables such as air pollutants, dietary habits and hormonal exposure are very difficult factors to analyze.

Our study did not find a statistically significant difference in the breast cancer group with respect to age at diagnosis. In support of this finding, Milikan et al. (2000) observed no correlation between null GSTM1 and age at diagnosis. As described above it is possible that other factors such as exposure to certain carcinogens or lifestyle may influence this result.

TABLE V

Presence of GSTM1 null deletion and breast cancer. Comparison between our results and the findings from the literature.

\begin{tabular}{lccccc}
\hline Study (No.) & Author & Cases N & Controls N & O.R & 95\% CI \\
\hline 01 & Linhares, 2005a & 105 & 278 & 0.74 & $0.45-1.20$ \\
02 & Vogl, 2004 & 2048 & 1969 & 0.98 & $0.86-1.12$ \\
03 & Sull, 2004 & Meta-analysis & Meta-analysis & 1.06 & $0.99-1.14$ \\
04 & Da Fonte de Amorim, 2002 & 128 & 256 & 0.28 & $0.42-1.00$ \\
05 & Milikan, 2000 & 322 & 334 & 0.03 & $0.27-0.34$ \\
06 & Gudmundsdottir, 2001 & 500 & 395 & 0.01 & $0.24-0.28$ \\
07 & Curran, 2000 & 129 & 129 & 0.03 & $0.46-0.52$ \\
08 & Egan, 2004 & 1144 & 1221 & 0.97 & $0.82-1.14$ \\
\hline
\end{tabular}

a: Ours results

$\mathrm{X}^{2}$ Test: Odds-ratio was estimated by the logistic regression model, assuming $95 \%$ as the confidence interval (CI). 
Concerning race, we did not find a statistically significant difference between the groups. Bailey et al. (1998) and Milikan et al. (2000) observed no association between GSTM1 null or GSTT1 null genotypes and breast cancer among women of black-African or Caucasian descent. Da Fonte de Amorim et al. (2002) suggested that polymorphism may decrease the risk of developing breast cancer only among nonCaucasian women.

ORs for null GSTM1 and menopausal status were not associated with breast cancer risk among pre- or postmenopausal women. These results are very similar to those by Garcia-Closas et al. (1999), who reported no association for GSTM1 null genotype in pre or postmenopausal women and Bailey et al. (1998) and Milikan et al. (2000) reported that GSTM1 null genotypes were not associated with breast cancer risk among pre- or postmenopausal women in African-American or Caucasian women. In contrast, Helzsouer et al. (1998) found that the GSTM1 null genotype was associated with an increased risk of breast cancer development, manifested predominantly in postmenopausal women. Park et al. (2003) observed a significant multiplicative correlation between GSTM1 and GSTT1 null genotypes and high-risk status of parity factor in all women and in premenopausal women $(\mathrm{p}<0.01)$, but not in postmenopausal women $(p>0.05)$; all of the aforementioned studies were primarily conducted exclusively with Caucasian women.

In breast cancer patients, the ORs for GSTM1 null genotypes were lower among women with a family history of breast cancer. Milikan et al. (2000) reported a slightly elevated risk among women with family history of breast cancer. Kelsey et al. (1997) reported no modification of ORs for GSTM1 based on family history. The negative associations for the GSTM1 polymorphism among women with a family history could be attributable to unknown genetic or environmental factors that interact with GST genes to increase the risk of breast cancer.

Smoking effects were modified only slightly by GSTM1 genotypes, as shown by previous studies (Kelsey et al., 1997;
Helzsouer et al., 1998; Milikan et al., 2000). Vogl et al. (2004) showed that single gene GST polymorphisms do not confer a substantial risk of breast cancer to their carriers. Furthermore, GSTs did not interact with smoking or reproductive history to modify cancer risk. Our results suggest that although GST enzymes are expressed in breast tissue (Forrester et al., 1990), polymorphisms in the GSTM1 gene do not play a role in modifying the association of smoking among breast cancer cases. Indeed, and in agreement with our results, Ishibe et al. (1998) study did not observe any difference in breast cancer risk for former smoking according to the M1 genotype.

GSTM1 genotype frequencies among breast cancer cases did not differ according to stage at diagnosis, axillary lymph node status or histological SBR grade. Additionally, ORs for GSTM1 and breast cancer did not differ when we stratified cases by clinical stage at diagnosis. These results are very similar to those in the literature, in relation to stage at diagnosis ( $p=0.9)$, shown by Milikan et al. (2000). Our results are consistent with these data because we observed no differences when we compared a variety of known prognostic factors using DNA samples from patients with and without the GSTM1 null genotype. These results suggest that clinical tumor features are not associated with GSTM1null genotype, although the reasons for these findings remain to be answered.

In conclusion, in the present study we were unable to demonstrate an association between the GSTM1 null genotype and breast cancer risk or between clinical and pathological findings. Due to the importance of the GST enzyme system in defense against potential mammary carcinogens, additional studies should be undertaken to fully determine its contribution to breast cancer. However, analysis of a larger number of individuals is necessary to further confirm these results, particularly as this is the first analysis involving a polymorphism of drug metabolizing enzymes and breast cancer risk incorporating variables such as smoking, reproductive history and several aspects of clinical pathologies. 


\section{ACKNOWLEDGMENTS}

We acknowledge the financial support of this research by FAPESP Grant 04/0553-9.

\section{REFERENCES}

BAILEY L, ROODI N, VERRIER C, YEE C, DUPONT W, PARL F (1998) Breast cancer and CYPIA1, GSTM1 and GSTT1 polymorphisms: evidence of a lack of association in Caucasians and African Americans. Cancer Res 58: 65-70

CAVALIERI EL, STACK DE, DEVANESAN PD, TODOROVIC R, DWIVEDY I, HIGGINBOTHAM S, JOHANSSON SL, PATIL KD, GROSS ML, GOODEN JK, RAMANATHAN R, CERNY RL, ROGAN EG (1997) Molecular origin of cancer: cathecol estrogen3,4-quinoses as endogenous tumor initiators. Proc Natl Acad Sci USA: 10937-10942

CURRAN JE, WEINSTEIN SR, GRIFFITHS LR (2000) Polymorphisms of glutathione S-transferase genes (GSTM1, GSTP1, and GSTT1) and breast cancer susceptibility. Cancer Letters 153: 113-120

DA FONTE DE AMORIM L, ROSSINI A, MENDONCA $G$, LOTSCH P, DE ALMEIDA SIMAO T, DE MOURA GALLO C, PINTO L (2002) CYP1A1, GSTM1, and GSTT1 polymorphisms and breast cancer risk in Brazilian women. Cancer Letters 181: 179-86

EGAN KM, CAI Q, SHU XO, JIN F, ZHU TL, DAI Q, GAO YT, ZHENG W (2004) Genetic polymorphisms in GSTM1, GSTP1, and GSTT1 and the risk for breast cancer: results from the Shanghai Breast Cancer Study and meta-analysis. Cancer Epidemiol Biomarkers Prev 13(2): 197-204

FORRESTER L, HAYES J, MILLIS R, BARNES D, HARRIS A, SCHLAGER J, POWIS G, WOLF C (1990) Expression of glutathione $S$-transferases and cytochrome P450 in normal and tumor breast tissue. Carcinogenesis (London) 11: 2163-2170

GARCIA-CLOSAS M, KELSEY K, HANKINSON S, SPIEGELMAN D, SPRINGER K, WILLETT W, SPEIZER F, HUNTER D (1999) Glutathione $S$ transferase class mu and theta polymorphisms and breast cancer susceptibility. J Natl Cancer Inst 91: 1960-1964

GUDMUNDSDOTTIR K, TRYGGVADOTTIR L, EYFJORD JE (2001) GSTM1, GSTT1, and GSTP1 genotypes in relation to breast cancer. Cancer Epidemiol, Biomarkers \& Prevention 10: 1169-1173

HELZLSOUER KJ, SELMIN O, HUANG HY, STRICKLAND PT, HOFFMAN S, ALBERG AJ, WATSON M, COMSTOCK GW, BELL D (1998) Association between glutathione S-transferase M1, P1, and, T1 genetic polymorphisms and development of breast cancer. J Natl Cancer Inst 90(7): 512-518

ISHIBE N, HANKINSON S, COLDITZ G, SPIEGELMAN D, WILLETT W, SPEIZER F, KELSEY K, HUNTER
D (1998) Cigarette smoking, cytochrome p4501A1 polymorphisms and breast cancer risk in the nurses' health study. Cancer Res 58: 667-671

KELSEY K, HANKINSON S, COLDITZ G, SPRINGER K, GARCIA-CLOSAS M, SPIEGELMAN D, MANSON J, GARLAND M, STAMPFER M, WILLETT W, SPEIZER F, HUNTER D (1997) Glutathione $S$ transferase class $\mu$ deletion polymorphism and breast cancer: results from prevalent versus incident cases. Cancer Epidemiol Biomarkers Prev 6: 511-515

MAUGARD CM, CHARRIER J, BIGNON YJ (1998) Allelic detection at glutathione S-transferase M1 locus and its association with breast cancer susceptibility. Chem Biol Interact 111 (112): 365-75

MILIKAN R, PITTMAN G, TSE C, SAVITZ DA, NEWMAN B, BELL D (2000) Glutathione Stransferase $\mathrm{M} 1, \mathrm{~T} 1$, and $\mathrm{P} 1$ and breast cancer. Cancer Epidemiol Biomarkers Prev 9: 567-73

PARK SK, KANG D, NOH DY, LEE KM, KIM SU, CHOI JY, CHOI IM, AHN SH, CHOE KJ, HIRVONEN A, STRICKLAND PT, YOO KY (2003) Reproductive factors, glutathione S-transferase M1 and T1 genetic polymorphisms and breast cancer risk. Breast Cancer Res Treat 78: 89-96

PARK SK, YIM DS, YOON KS, CHOI IM, CHOI JY, YOO KY, NOH DY, CHOE KJ, AHN SH, HIRVONEN A, KANG D (2004) Combined effect of GSTM1, GSTT1, and COMT genotypes in individual breast cancer risk. Breast Cancer Res Treat 88(1): 55-62

PARL FF (2005) Glutathione S-transferase genotypes and cancer risk. Cancer Lett 28 221(2):123-129

PERERA FP, ESTABROOK A, HEWER A, CHANNING K, RUNDLE A, MOONEY LA, WHYATT R, PHILLIPS DH (1995) Carcinogen-DNA adducts in human breast tissue. Cancer Epidemiol, Biomarkers \& Prevention 4: 233-238

RUIZ CAJ, SANTOS MAP (2001) Sistemas de defensa química em el hombre. Prevención em oncologia. Importância clinica del análisis de polimorfismos de susceptibilidad metabólica. In: www.sedet.es/sedet/pdf/ prevoncologiatxt.pdf: 1-8

ROSSINI A, RAPOZO DC, AMORIM LM, MACEDO JM, MEDINA R, NETO JF, GALLO CV, PINTO LF (2002) Frequencies of GSTM1, GSTT1, and GSTP1 polymorphisms in a Brazilian population. Genet Mol Res 1(3): 233-40

SEIDGARD J, VORACHEK WR, PERO RW, PEARSON WR (1999) Hereditary differences in the expression of the human glutathione S-transferase activity on transstilbene oxide are due to a gene deletion. Proc Natl Acad Sci USA 85: 7293-7297

SULL JW, OHRR H, KANG DR, NAM CM (2004) Glutathione S-transferase M1 status and breast cancer risk: a meta-analysis. Yonsei Med J 31 45(4):683-689

VOGL FD, TAIOLI E, MAUGARD C, ZHENG W, PINTO LF, AMBROSONE C, PARL FF, NEDELCHEVAKRISTENSEN V, REBBECK TR, BRENNAN P, BOFFETTA P (2004) Glutathione S-transferases M1, $\mathrm{T} 1$, and P1 and breast cancer: a pooled analysis. Cancer Epidemiol Biomarkers Prev 13(9): 1473-1479 